\title{
Melancholia and the New Biological Psychiatry
}

[W] hen there is perversion of the affective life, there will be morbid feeling and morbid action; the patient's whole manner of feeling, the mode of his affection by events, is unnatural, and the springs of his action are disordered; and the intellect is unable to check or control the morbid manifestations, just as, when there is disease of the spinal cord, there may be convulsive movement, of which there is consciousness, but which the will cannot restrain. ${ }^{1}$

Henry Maudsley (1867)

By the 1860s, the concept of disordered emotion as a physiological phenomenon was firmly established in British medicine. The physiological models of mental operations proposed by Carpenter and Laycock outlined in Chapter 2 were foundational for this development. As previously noted, at the same time as Laycock put forward his theory of cerebral reflex action, German physician Wilhelm Griesinger presented an almost identical model which he referred to as 'psychological reflex action' (psychische Reflexactionen). While neither Carpenter nor Laycock discussed mental reflex action in relation to depressive emotions, Griesinger applied his theoretical framework to melancholia and disordered mood. His textbook on mental pathology, first published in 1845 with a second, revised and expanded edition reaching a wide European audience in the 1860s, offered one of the century's most influential nosological descriptions of melancholia firmly anchored in a physiological model of emotion.

Å Jansson, From Melancholia to Depression, Mental Health in Historical Perspective, https://doi.org/10.1007/978-3-030-54802-5_4 
Griesinger inspired a new generation of physicians in Germany and beyond, including in Britain. In the late 1860s, up and coming asylum physician Henry Maudsley drew on Griesinger's work, as well as on the ideas of some of the most prominent scientific minds of the time, including Laycock and Carpenter, as well as Herbert Spencer and Charles Darwin. Maudsley sought to definitively merge physiology and psychology into a new scientific psychiatry that was equally concerned with classification and aetiology. His model of disordered mood and his nosological system had a far greater impact on subsequent psychiatric knowledge than is generally recognised by historians today. As a new scientific psychiatry was rapidly endorsed across Britain and the continent, numerous voices were added to those of Griesinger and Maudsley. In mapping the development of a biological model for melancholia and disordered mood, this chapter begins by tracing Griesinger's work on psychological reflexion and disordered mood from the 1840s until his premature death in 1868 . The chapter then looks more closely at the uptake up these ideas into British psychological medicine in the 1860s, culminating in the publication of the first edition of Maudsley's The Physiology and Pathology of the Mind in 1867. Finally, the story travels back to Germany and the model of melancholia presented by Richard von KrafftEbing in 1874. The chapter concludes by considering the relationship between melancholia and neurasthenia, in the context of North-American psychiatry in the last quarter of the nineteenth century.

\section{Wilhelm Griesinger: From Cerebral IrRitation to MENTAL DEPRESSION}

As a precocious young student Wilhelm Griesinger travelled around the continent for his medical training, receiving instruction from, among others, François Magendie in Paris. ${ }^{2}$ Upon his return to Prussia, he quickly rose among the ranks of a new generation of physicians advocating a scientific, academic psychiatry, and assumed the first combined chair of psychiatry and neurology at Berlin's Charité in 1864. Among his German contemporaries, Griesinger was best known and remembered as the controversial physician who attempted to bring about a radical reform of Prussian psychiatry. His bold modernisation programme presented in 1867 aimed to bring mental disorders out of isolated rural asylums and into a new generation of 'city clinics' situated in close proximity to university hospitals in order to facilitate research and clinical training. 
The proposal generated discord within the psychiatric community in the German states, a battle which would continue to rage after his premature death from appendicitis in $1868 .^{3}$

In 1843, a year after completing his psychiatric training under Alfred Zeller at the asylum in Winnenthal, Griesinger published an article entitled 'On psychological reflex action' (Ueber psychische Reflexactionen), ${ }^{4}$ in which he developed a physiological model of mental reflexion, and discussed its implications for psychopathology. Griesinger constructed much of his physiological model of reflexive action from what had been observed during experiments on living animals and what had been inferred from such research about that which scientists could not see. He suggested that existing experimental data showed that, as well as movements directed by the will, 'one could observe in animals a number of other muscle contractions triggered by centripetal sensory impressions'. Such impressions would, he argued, pass through the brain without alerting consciousness, and would result in muscle contraction being performed 'more completely' than in the case of conscious movement. ${ }^{5}$ In other words, unconscious motor reactions were potentially more powerful than those directed by conscious volition.

Griesinger then extrapolated this theory to suggest that involuntary and/or unconscious emotional reactions were more powerful than mental operations directed by the will. Like Laycock, he suggested that ideas could excite motor action as well as emotional reactions and the bodily manifestations accompanying the latter, adding an element that would become crucial to a physiological model for affective insanity. For Griesinger, external stimuli (such as Laycock's 'sound' or 'mention' of water) were not necessary to produce morbid emotion. Ideas kept in mental storages (geistiges Vorraths) could spontaneously and internally react upon one another. The 'totality of all exciting factors of [the brain]' was, he suggested, made up of both conscious and unconscious impressions, which were merged together to become new mental representations. That is, the brain stored and fused all impressions received, some of which passed through consciousness, and some which were stored without triggering awareness. All impressions were capable of reacting upon one another, and in doing so could synthesise and create new ideas, or mental representations (Vorstellungen), which could emerge endogenously, independent of external stimuli. When new impressions reached the brain from outside, ideas kept in mental storages were able to react upon previously stored images to produce novel ones. In a healthy 
brain, this process was self-regulating, maintaining the 'tone' of the brain, but in a disordered brain this kind of reactivity was the source of morbid symptoms such as depressed mood. ${ }^{6}$

Griesinger has been hailed as the founder of modern biological psychiatry, ${ }^{7}$ but like most of his contemporaries he struggled to make sense of the relationship between mind and brain. In the quest to explain that which verged on the inexplicable, metaphors were an invaluable device for nineteenth-century physicians. 'Tone' was one such metaphor. It was widely useful in nineteenth-century psychological medicine, but has not survived into the present. Tone came for Griesinger to denote both something tangible, like the physical tone of a muscle, as well as a kind of mental harmony, the maintenance of which was a prerequisite for a healthy mind. The tone of the brain, i.e. of the cerebral ganglia, was affected by the nature of mental images (Vorstellungen), so that, for instance, 'sad' images could serve to 'slacken' the tone of the brain. ${ }^{8}$

Two things in particular should be noted about Griesinger's physiological explanation of how ideas and emotions were generated in the brain. First, his theoretical framework must be understood against the backdrop of pre-nineteenth-century philosophical models of the mind. As Gerlof Verwey has shown, while Griesinger was explicitly committed to a biological view of mental pathology, there was a strong philosophical undertone throughout his work, which Verwey describes as 'an exemplary manifestation of the link between old and new'. ${ }^{9}$ This is demonstrated both by the abstract language used, and more specifically by the description of mental images as reacting upon one another to produce new ones. The latter bears resemblances to eighteenth-century associationist psychology, and would also re-emerge in mid-century Britain, where Herbert Spencer developed similar ideas within a new physiological framework. ${ }^{10}$

Second, the ability of the brain to react both to external and internal stimuli, and to produce from any combination of these entirely new impressions and ideas, formed the basis of a new biomedical model of mental disease. Moreover, as suggested above, for Griesinger it was the unconscious ideational reactions that were the most powerful. If an increasing number of negative impressions were stored and subsequently reacting both with further external irritants and with each other internally, the brain would be subjected to repeated 'irritation' [Reize]. Eventually, the process of automated or reflexive mental reaction would become disordered. The brain would then begin to produce morbid reactions, such as pathological feelings of displeasure, in response to factors that 
would not trigger such reactions in a healthy mind. ${ }^{11}$ Griesinger's model for describing the internal aetiology of mental disease followed the kind of physiological description offered by Billing and other contemporary European writers such as Müller (see Chapter 2). The 'irritation' of an organ leading it to become more sensitive or, in Billing's words, subject to 'morbid sensibility', served as a plausible metaphor for explaining affective insanity within a biomedical framework. In other words, language used to describe observable disease in organic tissue was now applied to make the unseen and unknown familiar and explicable. The analogous transfer that occurred here was ambiguous. The new physiological language was at once applied to talk about an organ - the brain-and its perceived function-the mind, and the operations of both of these, which, while for materialists like Laycock and Griesinger were perceived as strictly organic, could nevertheless not be observed with the naked eye, but only theorised according to language extrapolated from the observable somatic realm of internal medicine. What occurred here was not, then, simply a transfer from the physical to the psychological, but rather the creation of a new sphere within medical science, one in which physiology and psychology were not merely complementary to each other, but merged into a new system of knowledge.

Griesinger ended his essay by outlining what he perceived to be the implications of psychological reflex action for the study of insanity. In doing so he suggested that there were two basic emotional 'anomalies' which were foundational to all forms of mental disease. One was characterised by an 'elevated sense of self', and the other by a sense of 'dejection' and feeling of 'mental displeasure'. He went on to argue that 'in the infinite majority of cases, almost without exception, the starting point for all subsequent changes in mind which insanity entails are the latter states, those of mental depression'. ${ }^{12}$ It follows that he discussed melancholia at length in his textbook on mental pathology. He saw it as the first stage in mental disease, suggesting that it was therefore more treatable than other forms of insanity. The ability of physicians to recognise the onset of melancholia early on was, he argued, essential in order to facilitate early medical intervention. It was therefore imperative that all doctors were able to correctly detect and diagnose this form of insanity. ${ }^{13}$ 


\section{'Pain Is Awakened by the Slightest IMPRESSION': GRIESINGER'S MELANCHOLIA}

Griesinger favoured a modern version of the traditional tripartite division of insanity into melancholia, mania, and dementia, referring to these as the 'states of mental depression', the 'states of mental exaltation', and the 'states of mental weakness'. He also adhered to the theory of unitary psychosis which held that all forms of madness constituted different stages in the same disease. ${ }^{14}$ For Griesinger, comprehensive knowledge of states of mental depression [Depressionzustände] was imperative if one was to understand the onset and progression of mental disease more generally. These states, which included hypochondria and simple and delusional melancholia, were discussed at great length in the second extended edition of his textbook on mental pathology. ${ }^{15}$

The view that low mood was the first sign of oncoming mental disease meant that Griesinger argued forcefully for the importance of early detection and diagnosis of this form of insanity, since the progression from melancholia to mania and later dementia and death was a significant risk if symptoms were left untreated. The sooner clinical attention was brought to bear upon people displaying symptoms of melancholia, the greater the chance of rapid recovery. ${ }^{16}$ In conjunction with his proposal for urban clinics referred to above, he argued forcefully in favour of clinical training of students and of utilising psychiatric wards as sources of academic research. Psychiatry had to become a medical science, both as a practised speciality and as an academic discipline, and all medical students should receive proper instruction in how to identify and diagnose mental disease so that the milder forms - in other words the first stages of illness-would not go undetected. ${ }^{17}$ Central to Griesinger's reform plan was, then, an emphasis on milder forms of insanity - the states of mental depression. It was essential that physicians were familiar with a clear and comprehensive description of melancholia and that they understood what emotional disorders entailed, how they functioned, and how to identify them. Only the physician with proper psychiatric training could be sure to correctly distinguish between melancholia and normal, non-pathological low mood, a view that would often be repeated by British physicians later in the century.

While one historian has suggested that Griesinger 'based his definitions on borrowed cases and views', 18 he drew on cases of melancholia which he had come across when training under Alfred Zeller, as well as cases 
presented or published by other alienists. ${ }^{19}$ More importantly, however, the significance of Griesinger's work did not rest upon the originality of the case studies he produced, but on the biomedical model for insanity he presented. The framework for explaining affective insanity through psycho-physiological reflexion as the basis of disordered emotion would form an invaluable model for explaining affective disorders, particularly melancholia, throughout much of the century. While earlier physicians such as Pinel and Esquirol had begun to talk about 'affective', 'moral', or 'partial' insanity, Griesinger fashioned such disorders with an internal biomedical model which explained how emotion could become diseased, using the language of empirical science.

The second expanded edition of Die Pathologie und Therapie der Psychischen Krankheiten (1861), which was translated into English, began with a lengthy discussion of brain anatomy and physiology. Griesinger was unequivocal in the view that insanity had organic roots even when visible lesions could not be found, since mental activity was a physiological process, 'a special life form of the organism'. ${ }^{20}$ The textbook incorporated sections from his article on psychological reflex action and further elaborated the principles developed in the 1843 paper. In doing so, Griesinger highlighted an aspect of mind that constituted one of the more radical claims to emerge from physiological psychology at this time, and which he was not alone in making. Within a framework where all functions of mind (or, as Griesinger termed it here, 'Vorstellen,' roughly 'imagination') could be explained through the same physiological principles, the different mental faculties were hierarchically equal. ${ }^{21}$ Recalling his model of mental operations discussed above, he held that 'all the various mental acts which were formerly designated separate faculties (fantasies, will, emotions, etc.) are only different relations of the imagination with sensation and movement, or the result of the conflicts of mental representations with themselves'. 22

This act of constituting emotion, thought, and volition as equal, cerebral physiological processes, formed one of the cornerstones of theories of insanity suggesting that the mind could be diseased without causing delusion, and as such it helped facilitate and make plausible the medical condition 'simple melancholia'. By raising emotion to a level equal with cognition and volition, Griesinger made it possible for automated, unconscious interaction between these faculties to occur. Esquirol's monomanie and Prichard's moral insanity had conceptually suggested that in certain 
forms of insanity the passions were chiefly affected, and often constituted the cause of mental disease, but these models nonetheless insisted on some measure of intellectual derangement. The argument that one could suffer from mental disease without exhibiting any delusion of intellect or compromising of reason constituted a significant shift from earlier perceptions of what madness was. ${ }^{23}$

Griesinger went on to further develop the analogy of sensory-motor reaction as a model for how ideas and emotions were produced:

In the wider sense of the mind....every mental function, active or passive, and naturally also emotion, is a form of imagination. Emotion is an imagination which has arisen in the brain through immediate irritation of a centripetal fibre. A great number of mental images are not immediately provoked by irritation of the sensitive nerves, but are produced internally by the functions of the brain, which are independent of all sensorial excitation. They are also intimately dependent upon the traces which former sensorial impressions have left in the brain, and on the inward phenomena of sensation. ${ }^{24}$

As Griesinger had suggested in his article on the mental reflex, this ability of mental representations to react upon one another internally was key to understanding how mental disorders emerged. Just as reflexive action could be triggered solely within the realm of the mind, so was 'irritation' able to occur without external influence. Vorstellungen could be triggered into reaction 'not only by their normal, external irritants, but also by internal irritation'. ${ }^{25}$ Often, internal irritation would have its source elsewhere in the body, meaning that the immediate cause of insanity was in many cases some other bodily dysfunction or imbalance escaping conscious awareness. However, even if the original source of internal irritation was removed, the mental disorder may persist and develop independently. Moreover, 'such organic irritations do not usually excite new, clear and definite ideas but, in the first place, they cause those vague, indeterminate modifications of the mind which we call emotion (Gemütsbewegung)'. ${ }^{26}$ The fact that such internal irritation was often not consciously perceived helped explain, then, why the initial production of morbid mental action was one affecting emotion before the intellect.

Such morbid cerebral action could then give rise to the kinds of symptoms associated with melancholia. In discussing these, Griesinger again deployed the analogy of physical sensation, but this time explicitly. Mental 
images could, he suggested, be 'accompanied by pain or pleasure'. A disordered mind became subject to 'mental pain', which could at times be specific, linked to a particular mental image, but more often it was vague and diffuse, relating to 'emotion or the intellect as a whole': 'Much like in a bodily state of general pain and discomfort, so in the mind a causeless feeling of trepidation, anxiety, etc., when long continued, will eventually develop painful ideas'. ${ }^{27}$ It was in such general mental pain and 'lowness of spirits' which melancholia consisted. Griesinger began his chapter on the 'states of mental depression' by proclaiming that '[ $t]$ he fundamental affection in all these forms of disease consists in the morbid influence of a painful depressing negative affect - in a mentally painful state'. ${ }^{28}$ Recalling the discussion of 'depression' in Chapter 3, Griesinger was explicit in stating that he did not deploy the term in the strictly medical, physiological sense of lowered function, but as a descriptive term to denote a state of mind. In other words, mental depression did not denote 'passivity or weakness', or a 'suppression' of cerebral phenomena, rather, 'lively irritation of the brain and a commotion of the psychological processes are the foundation of this state; but the collective result of these (cerebral and psychic) processes for the general mood is a depressive or painful state'. ${ }^{29}$

While melancholia was often, as suggested above, initially induced by some form of internal bodily dysfunction subconsciously triggering cerebral irritation, it would at times also appear to be brought about in the first instance by 'normal' sadness or dejection such as 'grief' or 'jealousy'. Griesinger noted the problem of distinguishing the mental pain of melancholia from non-pathological 'painful emotion', but held that it would mark itself as different 'by its excessive degree, by its more than ordinary protraction, by its becoming more and more independent of external influences, and by the other accessory affections which accompany it'. ${ }^{30}$ What such 'accessory affections' consisted in depended in part upon which type of melancholia a person was suffering from. Hypochondria, according to Griesinger 'the mildest, most moderate form of insanity', was distinguished by a range of pronounced bodily complaints. These were in addition to 'the generic character of dejection, sadness, depression of mind, diminution of the activity of the will, and of a delirium which corresponds to this mental disposition'. However, in hypochondria 'the emotional depression proceeds from a strong feeling of bodily illness'. While hypochondria resulted in 'false conceptions' the intellect 
was for the most part uncompromised and the patient was able to follow logical reasoning.

The application of the mental reflex can be noted in the aetiology of hypochondria. The psychological feeling of bodily illness often emerged, Griesinger suggested, through irritation of the nervous centres arising from peripheral disease-often very obscured and concealed - of the viscera'. However, the perception of somatic dysfunction would take on a life of its own, persisting and growing independently of any bodily malady, and the more mental attention was focussed on these perceptions of illness, the stronger the feeling of bodily and mental discomfort would become. ${ }^{31}$ The states of mental depression would often commence with some measure of hypochondric features, at least if the original trigger for the disease was located elsewhere in the body. If medical attention was not brought upon the person afflicted, this 'state of vague mental and bodily discomfort' would pass into a persistent melancholia proper, characterised by a 'state of mental pain' which would be 'increased by every external mental impression'. ${ }^{32}$ This mental pain would soon begin to eclipse every other feeling of the sufferer, consuming every aspect of bodily and mental function. It 'consists in a profound feeling of illbeing, of inability to do anything, of suppression of the physical powers, of depression and sadness, and of total abasement of self-consciousness'. The entire character of the person so afflicted would eventually be transformed. The process by which feelings and ideas were produced would become so distorted, so diseased, that positive thoughts or feelings of joy were no longer possible. ${ }^{33}$

The disease process could equally start not with hypochondria but with simple melancholia. The two were similar in that both lacked the presence of proper delusion; the mind had not been fully consumed by the disease in that patients would be able to reason about their morbid feelings. However, with the physiological process of emotion having become disordered, the will was also affected. While patients were able to understand that their mental pain was unreasonable and unfounded, they were completely unable to master their morbid emotions. ${ }^{34}$ They could properly assess the 'objects of the outer world', but these produced 'an impression utterly different from what they were wont to do, of which the intelligent and educated sufferers can alone give a true description. "It appears to me" says such a melancholic, "that everything around me is precisely as it used to be, although there must have been changes." At first, the patient would be fully aware of this shift in their mental 
state, '[h]e even complains himself that his sensations are no longer natural, that they are perverted'. ${ }^{35}$ Simple melancholia, then, consisted in a state of disordered feeling accompanied by diminished volition. This disease model was made possible by the application of the reflex concept to all mental processes. In this way, the model of psychological reflex action developed by Laycock and Griesinger facilitated a view of insanity in which the idea of pathological emotionality was a plausible medical concept. The idea of disordered emotion as a physiological process was widely appropriated by British physicians in the decades that followed, bringing about a reconfiguration of melancholia in Victorian medicine.

\section{Henry Maudsley: Disordered EMOTION IN AN Evolutionary CONTEXT}

Henry Maudsley published extensively over more than four decades, with the bulk of his publications concerning the mind-body relationship and mental pathology. ${ }^{36}$ His preoccupation with mental disorders extended to include insanity and the law, an interest that grew out of his research on the physiology and psychology of 'morbid impulses'. His work was widely read by his peers, both in Britain and on the continent. Maudsley also published more on melancholia than almost any other of his British contemporaries. He embraced a theory of mind heavily anchored in physiological psychology, emphasising the significance of the 'latest advances in physiology, and....the present state of physiological psychology in Germany', drawing a parallel between research emerging from the German states and the theories of Bain, Spencer, Carpenter, and Laycock in Britain. ${ }^{37}$ However, unlike the British writers from which he derived his basic approach to the emotions, as a medical psychologist Maudsley was primarily concerned with the pathological aspects of mental phenomena. He was keen to stress the importance of establishing a solid theoretical foundation for his profession, and used his rising status in British psychological medicine to work towards this end. Danziger suggests that ' $[\mathrm{w}]$ hen Maudsley became editor of the Journal of Mental Science in 1862, its scope began to broaden to include relevant theoretical articles of a psychological or even philosophical nature'. ${ }^{38}$ His writings on mind and brain were at the core of the formation of British medical psychology as a scientific discipline concerned with empirical research into the causes, classification, and treatment of mental disease. Maudsley's physiological approach to mental pathology remained largely consistent 
throughout a career spanning more than four decades, but his nosology of insanity underwent several significant revisions. Key to these changes was that melancholia received increasingly more attention in his later work. His conceptualisation of melancholia rested upon a macro-classification developed early on in his published work that remained in place despite later nosological restructurings, and which saw mental disease divided into two umbrella categories: affective and ideational insanity.

Maudsley's framework for explaining mental phenomena was constructed around two related principles: reflex action, and organismenvironment interaction, with the former occurring as a result of the latter. Maudsley perceived reflex action to be the most basic function of the nervous system. Like Griesinger, Laycock, and Carpenter, he did not reserve automated reactions only for unconscious bodily function. Rather, reflexive action developed in an evolutionary fashion and served as the core mechanism behind conscious thought as well as emotion. In basic terms, Maudsley perceived reflexion as the 'relation between the individual organism and the external nature', a process which could become progressively more complex, and in its higher forms was understood as 'sensory perception' and 'sensorimotor reaction'. ${ }^{39}$ Drawing on ideas about environment-organism interaction developed by British psychologist Herbert Spencer in the 1850s, Maudsley suggested that a state of equilibrium between the external and the internal was at the core of all cerebral, and consequently all mental, functions. This was key to understanding the difference between normal and pathological emotionality:

Certainly [the nerve cells] are not inexhaustible centres of self-generating force; they give out no more than what they have in one way or another taken in; they receive material from the blood, which they assimilate, or make of the same kind with themselves; a correlative metamorphosis of force necessarily accompanying this upward transformation of matter, and the nerve cells thus becoming, so long as its equilibrium is preserved, a centre of statical power of the highest vital quality. ${ }^{40}$

This 'statical power' can be compared to Griesinger's 'tone' discussed above. Perceived by Maudsley as 'the condition of latent thought', of a mind at rest, it constituted the epitome of psychological health. Equilibrium was thus both a physiological principle of 'self-regulation' as well as a mental state. When perfect balance was maintained, the mind was in a 
state of rest-of 'latent thought'. Following from this, 'the manifestation of thought' could be understood as 'the change or destruction of nervous element' ${ }^{41}$ Such a 'change or destruction' would be caused by a stimulus triggering a reaction. Following Griesinger, Maudsley held that such stimuli need not come from outside, but could equally have their origin somewhere in the body. Interaction, then, was also an intra-organism process. Equally, Maudsley perceived, like Laycock and Griesinger, a type of non-motor reflex action occurring within the brain resulting in ideas or emotional reactions rather than muscle contraction. ${ }^{42}$ And like Griesinger, Maudsley suggested that emotional and ideational reactions to internal or external stimuli could occur without conscious awareness, producing a feeling of which the individual would not know the source, meaning it was prone to result in 'illusions with regard to the cause'. Such illusions often constituted symptoms of insanity, and were most frequently seen in asylum patients, he argued. ${ }^{43}$

In Maudsley's model of the mind the gradual development of consciousness, both within each individual and in an entire species across time, began as a reflexive relationship between environment and organism, where the former would act upon the latter, causing a corresponding reaction and, subsequently, transformation. In higher animals, this reflexive relationship formed the basis of the creation of new ideas. Like Griesinger, he suggested that impressions received by the brain would disperse internally and turn into 'ideas or conceptions', which could be 'pleasurable or painful, or have other particularly emotional qualities'. ${ }^{44}$ As suggested above, Maudsley also followed Griesinger in arguing that psychological reflex action could occur both subconsciously and involuntarily; however, involuntary mental reflex action could also take place with the consciousness alerted yet 'in direct defiance of volitional effort'. ${ }^{45}$ In the same manner as ideas and emotions the will was, according to Maudsley, the product of 'molecular change in a definitively constituted nervous centre', meaning that volition was, ultimately, 'excited into activity by the appropriate stimulus'. ${ }^{46}$

For Maudsley, then, volition did not belong to a higher realm independent from thought and emotion, it was a function of human biology, a physiological reaction to stimulus, if one that could be honed through persistent practice to function in a certain way. Not everyone who submitted to a physiological theory of mind was equally prepared to do away with the concept of free will. As discussed in Chapter 2, Carpenter divided the nervous system into hierarchically organised sections, with 
the intellect (containing the will) belonging to the highest sphere and immune from automated reaction. When describing psychological as opposed to sensory-motor reflex action, Maudsley deployed Carpenter's term 'ideo-motor' action, denoting its function as analogous to sensorymotor action. In Carpenter's original use of this term the principle extended as far as 'emotions' and 'instincts', and in some instances also 'ideas', but when it came to volition he would not concede to a reduction of the will to physiological processes.

When Maudsley used Carpenter's 'ideo-motor action', then, he also subtly changed its meaning. For Maudsley, all reactions of the mind were essentially equal. This meant that emotion was a reaction of the cerebral hemispheres just like volition and ideation (cognition). However, Maudsley differentiated emotion in other ways. Recalling his earlier remarks about a state of mental harmony, emotional reactions were for Maudsley what ensued in response to any form of imbalance, or unequal relationship, between the individual and their environment:

As long as the ideas or mental states are not adequately organized in correspondence with the individual's external relations, more or less feeling will attend their excitation; they will, in fact, be more or less emotional. When the equilibrium between the subjective and objective is duly established, there is no passion, and there is but little emotion. ${ }^{47}$

Since any mental reactions could be triggered by external and internal stimuli alike, this was also the case for the emergence of pathological emotionality. In describing the process by which emotion would arise Maudsley stated that ' $\mathrm{t}]$ he equilibrium between the individual and his surroundings may, in fact, be disturbed by a subjective modification, or an internal commotion, as well as by an unwonted impression from without' ${ }^{48}$ The environment could act upon the individual, but so could the individual's own bodily operations, which in turn had the ability to affect the external-internal balance.

The kind of internal commotion described above would generally consist in some form of 'derangement' elsewhere in the body. This would then affect the brain, resulting in cerebral morbidity. Once this state had been reached, virtually any impression, including those that would trigger feelings of pleasure in a mind free from disease, would cause painful emotions. ${ }^{49}$ This mental pain was made into a coherent medical phenomenon through being analogous to physical pain. This was the state 
that would prevail when the equilibrium of the mind was permanently upset, or, rather, when the 'tone' was disturbed. There is no reference to Griesinger here, but Maudsley's description of how morbid ideas and emotions emerge strongly echoes that of the German psychiatrist. The kinds of mental reactions that were likely to occur in response external or internal stimuli would depend on the 'psychical tone, the tone of the supreme nervous centres', which was different in each individual as it was the long-term product of 'past thoughts, feelings, and actions, which have been organised as mental faculties'. ${ }^{0}$

While emotional reactions were produced in the brain, they would, through the various nervous connections of the human body, exert influence over bodily functions and trigger reactions of 'the organic movements, or the more intimate processes of nutrition'. ${ }^{51}$ Emotion as physiological mental reflex action was a two-way process, in that it could be set off by some activity elsewhere in the body which would affect the brain and produce emotion, the latter which would then effect some other peripheral reaction (for instance, trembling). Moreover, yet another reciprocal action would occur from this: any emotion 'is rendered stronger and more distinct by the existence of those bodily states which it naturally produces'. ${ }^{52}$ Cerebral and somatic reactions, both of which featured in the production of emotions, were mutually constitutive and reinforcing, maintaining the emotional state produced. ${ }^{53}$ This process was particularly significant in the case of morbid emotional activity:

Consequently, it is found that, as the effect of the depressing passion is felt by the victim of a local idiosyncrasy in his weak organ, so inversely the effect of a weak or diseased organ is felt in the brain by an irritability or disposition to passion, a disturbance of the psychical tone. The phenomena of insanity will furnish the best illustrations of this sympathetic interaction. ${ }^{54}$

\section{TOWARds a Nosological Reification of MELANCHOLIA}

According to Maudsley, not all individuals were equally prone to insanity. While morbid states may at times appear to be produced by a particular event or sudden 'mental shock', this would only be the immediate triggering factor. The conditions of mental disturbance consisted in an accumulation of physical and psychological factors over time, thus the 
cause of mental disease could be correctly discerned by means of '[a] complete biographical account of the individual'. 55 The process whereby the conditions of mental disease were gradually developed in a person was dependent upon the individual's capacity for adaptation. In conclusion, then, the aetiology of mental disease was for Maudsley ultimately a product of evolutionary law, where a healthy mind was 'the consequence and evidence of a successful adaptation to the conditions of existence', whereas mental disorder signified 'a failure in organic adaptation to external conditions', leading to 'disorder, decay, and death'. ${ }^{56}$

Such 'disorder, decay, and death' would in most cases begin with affective disturbance. Because disordered emotion could, in Maudsley's view, manifest without intellectual delusion, he rejected 'the present artificial classification, which is not really in conformity with nature'. ${ }^{57}$ This classification or (various, similar) classifications which Maudsley referred to were commonly the product of cumulated models of some of the most often cited European alienists of the early nineteenth century, specifically Pinel, Esquirol, Guislain, and Griesinger. The major standard British textbook at the time, Tuke and Bucknill's Manual of Psychological Medicine, ${ }^{58}$ adopted a nosology broadly based chiefly on Griesinger and Esquirol. In particular 'monomania', a British version of Esquirol's disease concept, served as an umbrella category for a number of sub-syndromes. These were considered various forms of 'partial' insanity, in other words disorders where some part of the power of intellectual reasoning was preserved.

As discussed in Chapter 3, the French physician's 'monomania' had been primarily defined as insanity relating to one specific object. ${ }^{59}$ This category, and the many modifications of it, allowed for madness to be chiefly of emotional character, with only part of the intellect affected. However, it did not categorically distinguish between madness with or without delusion. In the 1858 edition of Bucknill and Tuke's textbook, melancholia was subsumed under 'monomania', though the authors recognised a version of it presenting 'without delusion' ${ }^{60} \mathrm{~A}$ separate category, 'emotional insanity', did not include forms of melancholia but rather chiefly mania and various forms of morbid impulsivity such as the 'homicidal impulse'. In sum, forms of madness where some form of ideational derangement was present. ${ }^{61}$ Such a system of classification was, however, construed around an 'artificial exactness', Maudsley argued, and did not correspond to the endless plurality and complexity of mental disease. Would a nosological system not be more 'scientific', he asked, 
'[i]f a broad division was made of insanity into two classes, namely, insanity without positive delusion and insanity with delusion, in other words, into affective insanity and ideational insanity; and if the subdivision of these into varieties were subsequently made'? ${ }^{62}$ The nosology Maudsley presented, then, insisted upon a marked division between mental disorders where partial or complete delusion was present, and illness where only the emotions were affected (Table 4.1).

One significant consequence of this division was that melancholia did not appear as a single, unified disease category. It was not primarily defined and organised according to its specific symptoms, but instead according to their source and character: that is, according to whether those symptoms consisted only in disordered emotion or in disordered ideation (or cognition) as well. Melancholia shared the category affective insanity with mania and with Maudsley's 'moral alienation', the latter which can be seen as one of the many variations of Prichard's moral insanity. The term 'moral' could mean either 'psychological' or moral as in ethical. Maudsley used it to mean the latter, a perversion of a person's moral character, resulting from a morbid emotional state. Maudsley's nosology was foundational for the idea of melancholia as a biomedical disorder of the emotions, since it unambiguously established as a medical principle the concept of pathological mood without concomitant intellectual derangement. This chapter and Chapter 2 showed how Laycock and Griesinger developed mental reflex models which allowed for the idea of pathological emotions, and how the latter stressed the role of the

Table 4.1 Classification of insanity (The Physiology and Pathology of the Mind, 1867)

\section{Affective insanity}

1. Maniacal Perversion of the Affective Life. Mania sine Delerio

2. Melancholic Depression without Delusion. Simple Melancholia

3. Moral Alienation Proper
Ideational insanity

1. General Mania (acute \& chronic) Melancholia (acute \& chronic)

2. Partial Monomania Melancholia

3. Dementia (primary \& secondary)

4. General Paralysis

5. Idiocy (incl. Imbecility) 
emotions as the key to understanding the emergence and progression of mental disease, arguing that all forms of insanity began with disordered emotions and mental pain. With Maudsley's nosology, disordered mood was unequivocally cemented as a specific, distinct form of mental disorder.

Maudsley was aware of the significance and implications of his system of classification; indeed, its implications for the diagnosis, treatment, and future research into insanity were his motivation for presenting it. Any nosology that did not fully and clearly recognise that a person could be gravely disturbed without being delusional was highly problematic, even dangerous. 'To insist upon the existence of delusion as a criterion of insanity', Maudsley argued, 'is to ignore some of the gravest and most dangerous forms of mental disease.' As discussed above, when the brain would begin to produce morbid emotions, these would become all-consuming, further entrenching the conflict between the internal and external life which was at the core of this disordered process as well as of healthy emotional reactions. Since this process occurred reflexively, analogous to automatic sensory-motor action, it was beyond the control of volition. To sum up, then,

when there is perversion of the affective life, there will be morbid feeling and morbid action; the patient's whole manner of feeling, the mode of his affection by events, is unnatural, and the springs of his action are disordered; and the intellect is unable to check or control the morbid manifestations, just as, when there is disease of the spinal cord, there may be convulsive movement, of which there is consciousness, but which the will cannot restrain. ${ }^{63}$

Yet, this total engulfment of the individual by mental pain could take place without distorting the intellect. In the decades that followed a number of physicians, including Maudsley himself, would argue that it was this very feature which made the emotional pain of melancholia so difficult for sufferers to bear, and as such was a crucial factor in driving melancholics to suicide. 


\section{Melancholia on the Continent: Folie Circulaire and Psychische Neuralgie}

The nosological status of melancholia was also being renegotiated on the continent in the mid-to-late nineteenth century. As shown in Chapter 3, Esquirol had proposed lypemanie as a replacement category for melancholia, indicating that it was a subspecies of monomania. The term never took off, but in the 1850s one of his protégés, Jules Baillarger, offered a more durable reconceptualisation of melancholia. Medical writers across Europe had occasionally suggested that the symptoms of melancholia could in some cases pass into those of mania and back again. For Baillarger, this oscillating process constituted a variety of madness, which he described in a paper read at the Imperial Academy of Medicine in Paris in 1854, and which was translated for an English-speaking audience the same year. Baillarger argued that while the two conditions appeared so much each other's opposites as to be 'strangers to each other', on the contrary, 'in most cases melancholia follows mania, and vice versa, as if there were a secret union between these two diseases'. ${ }^{64}$ A similar proposition had, apparently unbeknownst to Baillarger, been made in a published article three years previously by fellow alienist JeanPierre Falret, who in response to Baillarger's paper remarked that he had been observing this form of mental derangement for some time on asylum wards, and had concluded that it was not merely 'a variety, but a specific form of insanity'. Falret had named this condition folie circularie-circular insanity. He viewed it as a more or less lifelong, chronic illness, but with milder symptoms than were often found in melancholia and mania proper. ${ }^{65}$

The apparent discovery of this new disease was noted in Britain and was often referred to in discussions of melancholia in the decades that followed. While it was never widely appropriated in Victorian medical literature, British writers told of similar observations among asylum patients. Maudsley, for instance, suggested that melancholic symptoms could sometimes be a precursor to mania, and were prone to return again during the convalescent phase of the disease. ${ }^{66}$ Thomas Clouston noted the presence of a form of mental disease that had 'been called by the French "circular insanity", but suggested that a more appropriate term was that of 'alternating insanity', as in his view this type of madness was marked by distinctive changes in the person's overall character. 'Such men have three distinct lives', he argued, 'each of which is characterised 
by its own tastes, habits, dispositions, and modes of intellectual activity'. ${ }^{67}$ George Savage remarked in a discussion on mania that a form of illness referred to as folie circulaire had been observed, in which 'mania is succeeded by melancholia, to be again succeeded either by a period of health, or by a fresh attack of mania. ${ }^{68}$ However, Savage held such cases to be 'extremely rare' among English lunatics, suggesting that in most of the patients under his care who had exhibited such a circular symptom picture, the proper diagnosis was one of 'recurrent mania', sometimes ending in dementia. ${ }^{69}$ This statement largely reflected the view of his peers; while some writers used the term 'circular insanity' or folie circulaire, it was predominantly to talk of a subvariety of melancholia or mania. $^{70}$

If the French model of circular insanity failed to gain widespread theoretical popularity or practical use in Britain at the time, German late nineteenth-century conceptions of melancholia were more extensively appropriated. By the mid-1870s, psychiatry was an established academic discipline across German-speaking Europe, particularly in former Prussia. Proponents of the new, scientific psychiatry were keen to define their work in opposition to the more traditional asylum-focused alienism, where both clinical practices and theoretical discussions had been chiefly aimed at management and confinement of lunatics. There was a strong focus on diagnostics, treatment, and clinical instruction for medical students of mental disease, and the discipline had from the start assumed a heavy leaning towards neurological conceptions of madness. As noted above, Griesinger had prior to his untimely death been a driving force in the early stages of this process, aptly symbolised by his appointment to the first combined chair in psychiatry and neurology at the Charité in Berlin in 1865..$^{71}$ However, Griesinger's model of melancholia remained partly wedded to traditional ideas; he maintained the old tripartite division of insanity, and while melancholia was fashioned with a modern, biomedical explanatory model, the symptom picture was little changed from that found in the works of earlier writers. While highlighting the modern 'mental depression' as a defining symptom, grief, despondency, and sadness were also primary features of Griesinger's melancholia, and he placed significant focus on the patient's overall constitution, physiognomy, and temperament. There was, moreover, little talk of suicidality. ${ }^{72}$

Less than a decade after Griesinger's death, in 1874, Austrian neurologist and psychiatrist Richard von Krafft-Ebing published a short monograph entitled Die Melancholie: Eine Klinische Studie. Krafft-Ebing would 
later become famous across Europe for his widely appropriated work on sexual pathology; however, his impressive catalogue of publications also included a comprehensive general textbook on mental disease aimed at students and practitioners, which appeared in several editions. ${ }^{73}$ While the monograph on melancholia was never translated into English, significant parts of it were later absorbed into the English language version of his textbook on insanity, thus reaching a wider audience in Britain. ${ }^{74}$ Krafft-Ebing's approach to emotion can be seen as closely aligned with Laycock's and Griesinger's. Emotion was a neurophysiological reaction analogous to action elsewhere in the body. In this way, melancholia was for Krafft-Ebing a form of 'mental neuralgia' (psychische Neuralgie), which was functionally different from physical neuralgia. The latter took the form of a 'bodily pain' along the 'sensory paths' of nervous transmission. In its psychological equivalent the brain was the object of 'excitement', producing 'an alteration of consciousness' manifesting as 'mental (geistiger) pain, a feeling which finds its expression through a change in mood'. ${ }^{75}$ This psychic pain defined and dominated the overall mental state of the melancholic, and arose from internal rather than external causes.

Similar to Griesinger's model, this painful state of mind in KrafftEbing's melancholia was the result of repeated irritation of the brain. Mental neuralgia characterised the early stage of the illness, at which point neither the physiological process nor external symptoms were necessarily qualitatively different from those of a healthy mind. It follows that someone not trained in the skill of detecting mental disease would look for and expect to find the real cause of the mental pain. Here, however, lied the distinction between ordinary suffering and the suffering of simple, or non-delusional melancholia: the latter must be understood as an abnormal reaction to normal circumstances. Following Griesinger, Krafft-Ebing held that the melancholic brain would 'overreact' to external stimuli, so that all events, even those that would normally be a source of happiness, produced painful emotions. ${ }^{76}$ 'Under such circumstances', he suggested, the origin of the mental pain 'is not psychic, but organic. It is the expression of a disturbance of nutrition in the psychic organ'. ${ }^{77} \mathrm{In}$ this pathological state, painful emotions would become self-perpetuating, with every impression brought upon the sick person becoming a source of further pain. Even the kinds of 'distractions' that would normally have a soothing or comforting influence, such as religion, would only produce further agony. Eventually the melancholic would reach a state where they 
were 'unable to rejoice over anything, but...equally unable to experience sadness'. ${ }^{78}$

Krafft-Ebing's work, then, contains one of the earliest descriptions of melancholia as a mental state characterised not by excessive low mood, but rather by an absence of feeling. Profound melancholia was, he argued, characterised by a lack of emotion-the patient becoming 'feeling-less' (Gefübllos) and 'mood-less' (Gemühtlos). This state of emotional apathy would often become so intolerable that the melancholic sufferer would eventually be driven to take their own life, prompting Krafft-Ebing to suggest that ' $[\mathrm{t}]$ he majority of people who commit suicide are melancholics'. As will be seen in the next chapter, this perceived suicidality of melancholics placed a significant burden and responsibility on asylum staff, as such patients had to be kept under constant surveillance. In Krafft-Ebing's words, '[t] he cunning and perseverance exhibited by such sick people in the pursuit of their suicidal intentions' was so 'remarkable' that even the 'straitjacket is no guarantee against suicide'. ${ }^{79}$

\section{MoOd Disorder or Nervous EXHAUSTION? Melancholia and Neurasthenia}

Krafft-Ebing's melancholic would sink so deeply into despair that they would eventually lose the ability to feel anything at all, even sadness, a defining symptom of traditional melancholia. This kind of emotional apathy was equally characteristic of neurasthenia, or nervous exhaustion, a 'disease of civilisation' emerging in the second half of the nineteenth century. Melancholia and neurasthenia were two separate conditions, situated within different explanatory frameworks and with different symptomatologies. But much like in the present, diagnostic boundaries in the nineteenth century were often fuzzy and fluid, and the neurophysiological framework for explaining mental disease expounded by Griesinger, Maudsley, Krafft-Ebing, and others coexisted with a more general discourse on 'nerves' as a source of a wide variety of mental and physical symptoms for which no organic cause could be found. As one historian notes, much in the same way as 'an epileptic fit might be explained in terms of excessive build-up and then discharge of nervous energy, so the symptoms of depression, fatigue, melancholia, and nervous breakdown could be attributed to the ebbing of the same force'. 80 'Mental depression' in particular, a symptom denoting a mind 'pressed down', served to bridge 
melancholia and neurasthenia, and have led scholars to discuss nineteenthcentury experiences of low mood, fatigue, sadness, inertia, anxiety, and despair under the general heading of 'depression'. ${ }^{81}$

While it is not possible to fully disentangle the two conditions from each other, it is important to note their clear differences as well as their similarities. Neurasthenia emerged in the United States in the 1860s. E.H. van Deusen and George Beard are both credited with coining the term, but the latter is generally regarded as its chief proponent. The symptoms of neurasthenia as described by Beard in his famous monograph on the condition tell of a diffuse and all-encompassing illness, a mental and bodily malaise that left few parts of the human anatomy untouched. Sufferers of this disease would, according to Beard, complain of a diverse assortment of symptoms, including headaches, tenderness of the scalp, digestive problems, visual disturbances, noises in the ears, cramps, heart palpitations, back pain, dry skin, tenderness of the teeth and gums, insomnia, drowsiness, mental irritability, hopelessness, and morbid fear. ${ }^{82}$ Misbach and Stam suggest that neurasthenia was seen by some as a more attractive diagnosis as it was predominantly conceptualised as a somatic condition rather than a mental disorder, and therefore came with less stigma attached. ${ }^{83}$ This made it particularly popular with the upper classes, and to the extent the diagnosis was deployed in Europe this was primarily in the context of private practices rather than on asylum wards.

Much like the language around emotion, the discourse on nerves that underpinned neurasthenia underwent a reconceptualisation in the nineteenth century. The idea of 'nerves' as the cause and manifestation of poor mental and physical health had been popular in early modern Britain, and was famously discussed at length by eighteenth-century physician George Cheyne in his treatise on 'the English malady'. ${ }^{84}$ The eighteenthcentury explanatory framework was, however, different from that of the following century, the former attributing nervous suffering to 'weak, loose, and feeble or relaxed nerves', ${ }^{85}$ suggesting that this was a problem primarily affecting the higher social strata whose way of life had made them particularly sensitive. Weak nerves were linked to 'the high-living, prosperity, and progress unique on such a wide scale in eighteenthcentury England'. ${ }^{86}$ From the mid-nineteenth century onward, however, nervous disorders became explicitly understood as exhaustion resulting not from affluent living, but from the increasing pressures of 'brain work' in a rapidly expanding capitalist society. ${ }^{87}$ Moreover, it was no longer the loss of vital fluid that was the main source of disease, but rather 
the loss of 'force'. ${ }^{88}$ As Anson Rabinbach has shown, the human body became metaphorically perceived as an engine subject to the same laws as heat powered machinery. ${ }^{89}$ This new way of conceptualising health and sickness borrowed its language and explanatory model from the theory of thermodynamics, which merged with terminology derived from economics. The increasing popularity of the word depression as a medical symptom must be understood in the context of these developments, which highlight the role of this symptom in blurring the line between emotional disorders such as melancholia and the more somatically framed concept of nervous exhaustion. In this context the word 'depression' became a more frequent and prominent part of medical terminology, specifically in regards to mental states. ${ }^{90}$ The growing popularity of this word as a feature both of nervous exhaustion and medical melancholy can no doubt in part account for the tendency among contemporary scholars to equate nineteenth-century nervous conditions as well as melancholia with 'depression' as understood in late twentieth- and twenty-first-century medical discourse.

Both melancholia and neurasthenia were somatically framed, and both were unlikely to turn up structural organic evidence of disease. In this way, both conditions could be seen to straddle the increasingly fluid boundary between normal and pathological states, but while there was certainly some overlap between the two, it is crucial to note that they were fundamentally different conditions. Nervous exhaustion was brought about by external pressures, whereas melancholia was primarily the result of an internal pathology - though as we have seen, this mental state could be triggered by both internal and external factors, making the aetiology of melancholia ambiguous. Neurasthenia was a poorly defined, diffuse somatic condition whose validity was contested among many psychiatrists, whereas melancholia was a clearly demarcated mental disease with a coherent symptomatology centred on depressed mood, mental pain, and suicidality, and in the more severe stages of the illness inertia, bodily retardation, delusions and hallucinations, and in some cases catatonia. Melancholia was unequivocally perceived as a form of insanity. However, while neurasthenia is today an object of study for historians of psychiatry, its status in the late nineteenth century was less clear. It was originally conceptualised as a somatic condition, but towards the turn of the century as physicians had repeatedly failed to turn up organic evidence of disease, the symptoms were increasingly seen as 'functional'. As a consequence, the category moved into the realm of psychiatry, 
eventually becoming reconceptualised as 'neurosis' within the emergent psychoanalytical tradition. ${ }^{91}$

\section{Melancholia Across the Atlantic}

The complex relationship between melancholy and neurasthenia must also be understood with reference to geographical and cultural differences. The neurasthenia diagnosis never really took off in Europe's medical circles. Beard himself remarked that neurasthenia was far more common in North America than in Western Europe, highlighting a divergence between the two realms. Melancholia was deployed as a diagnosis in North-American asylums and US physicians published on the disease, but the diagnosis was primarily shaped and standardised through the works of British and German authors. Descriptions of the condition in North-American journals demonstrate the influence of European psychiatry on US conceptualisations of melancholia. In a lecture on melancholia delivered in 1876 Daniel Kitchen, head of New York's Blackwell Island asylum, endorsed a model of disordered mood anchored in physiological psychology. Echoing Griesinger, Kitchen noted that all forms of insanity began with disordered action of 'the emotional reflex centres'. Like Griesinger, he also appeared to subscribe to the unitary model of mental disease, referring to melancholia as the 'first stage' of insanity. Kitchen described the progression from simple, non-delusional melancholia to more severe forms, in which both delusions and hallucinations could develop. He also noted the prominence of suicidal tendencies, which, he argued, may cause patients to try to convince the physician that they were well enough to be released 'in order to obtain their object'. Kitchen's description of melancholia illustrates the extent to which the diagnosis was becoming standardised in the West in the second half of the century as a clearly defined condition with a largely coherent symptomatology. Indeed, Kitchen remarked that diagnosing melancholia was 'not difficult' as 'nearly all cases' were 'self-evident'. ${ }^{92}$

Ira Russell, writing for the Alienist and Neurologist in 1881, equally placed melancholia in a psycho-physiological framework. Drawing on the works of British physicians such as Tuke and Bucknill, Crichton Browne, and Maudsley, Russell suggested that ' $[\mathrm{m}]$ orbid states...of the centres of organic sensation in reciprocal action and reaction may give rise to hypochondriasis or melancholia'. ${ }^{93}$ He moreover strongly emphasised the importance of being vigilant towards suicidal propensities in melancholics, 
arguing that the 'tendency of melancholics to commit suicide, renders it absolutely necessary that they should be carefully watched.' 94 Here Russell echoed a claim forcefully made by Maudsley, Savage, and other British physicians of the period, as will be seen in the next chapter. In explaining the suicidality of melancholics he cited Maudsley, who 'says it is due to the loss of the love of life'. Speculating about the physiological basis for this deviation from what was at the time considered an evolutionary fact, Russell pondered whether there might 'be a cerebral center that presides over the instinctive love of life' and that in the case of suicidal melancholics 'that center' had become 'organically or functionally diseased'. ${ }^{95}$

\section{CONCLUSION}

By the last quarter of the century, a biomedical model of melancholia as a condition of disordered mood was widely endorsed across Western Europe and North America. This chapter has shown how Griesinger developed a theory of psychological reflex action similar to that put forward by Laycock, which he subsequently deployed to explain how emotion became disordered through repeated irritation of the brain, eventually resulting in pathology. This pathological mental state, which in the early stages would usually manifest as simple melancholia, or sometimes hypochondria, could deteriorate to the point where delusions and hallucinations developed. For Griesinger and some other contemporaneous writers, melancholia was the first in three stages of mental disease, meaning that if left untreated it was likely to progress into mania, and eventually dementia and death. Others, such as Maudsley, did not subscribe to the unitary psychosis model, conceiving instead of melancholia as a distinct illness category (or categories). These differences should not, however, be overstated. From the point of view of aetiology and diagnostics, the internal model and the symptomatology of melancholia were largely the same whether classified as an independent disease or as the first stage of insanity. Towards the end of the century, the diagnosis was increasingly standardised in published literature, where it came to centre on four key symptoms: mental pain, depression, suicidality, and religious delusions. This is the focus of the next chapter. 


\section{Notes}

1. Henry Maudsley, The Physiology and Pathology of the Mind (London: Macmillan, 1867), 302.

2. Gerlof Verwey offers an engaging account of Griesinger's life in Wilhelm Griesinger: Psychiatrie als ärztlicher Humanismus (Nijmegen: Arts \& Boeve, 2004).

3. See Wilhelm Griesinger, "The Care and Treatment of the Insane in Germany," Journal of Mental Science 14, No. 65 (1868): 1-34. The original article, which caused a stir among his German peers, was published in the introductory issue of the Archiv für Psychiatrie und Nervenkrankheiten, which Griesinger launched together with Ludwig Meyer and Carl Westphal in 1867. For the events leading to the creation of this journal (which sought to distance itself from the more traditional asylum journals), see Alexander Mette, Wilhelm Griesinger: Der Begründer der Wissenschaftligen Psychiatrie in Deutschland (Leipzig: Teubner, 1976), 58-67. For more detailed commentary/discussions of Griesinger's reform program see: Eric J. Engstrom, Clinical Psychiatry in Imperial Germany: A History of Psychiatric Practice (Ithaca, NY: Cornell University Press, 2004), 51-87; Kai Sammet, “'Ueber Irrenanstalten und deren Weiterentwicklung in Deutschland': Wilhelm Griesinger im Streit mit der konservativen Anstaltspsychiatrie 1865-1868" (PhD diss., Hamburg, Münster, 2000).

4. Wilhelm Griesinger, "Ueber psychische Reflexactionen: Mit einem Blick auf das Wesen der psychischen Krankheiten," reprinted in Gesammelte Abhandlungen, Ersters Band: Psychiatrische Abhandlungen (Amsterdam: E.J. Bonset, 1968 [1843]).

5. Griesinger, "Ueber psychische Reflexactionem," 4-5.

6. Griesinger, "Ueber psychische Reflexactionem," 11-12.

7. Edward Shorter, A History of Psychiatry: From the Era of the Asylum to the Age of Prozac (New York: Wiley, 1997), 76.

8. Griesinger, "Ueber psychische Reflexactionem," 10-11.

9. Gerlof Verwey, Psychiatry in an Anthropological and Biomedical Context: Philosophical Presuppositions and Implications of German Psychiatry, 18201870 (Dordrecht: Kluwer, 1985), 87.

10. Herbert Spencer, The Principles of Psychology (London: Longman, Brown, Green \& Longmans, 1855).

11. Griesinger, Griesinger, "Ueber psychische Reflexactionem," 24-25, 3536.

12. Griesinger, "Ueber psychische Reflexactionem," 35.

13. Wilhelm Griesinger, "The Prognosis in Mental Disease," Journal of Mental Science 11 (1865): 317-321. 
14. Verwey suggests that Griesinger built his theory of unitary psychosis partly on his mentor Alfred Zeller's beliefs, and partly on the model developed by Belgian physician Joseph Guislain; Verwey, Psychiatry, 141-143. Guislain's psychiatric nosology was influential across Western Europe in the first half of the century. See Joseph Guislain, Traité sur l'Aliénation Mentale et sur les Hospices des Aliénalés (Amsterdam: J. van der Hey, 1826). Despite the moderate popularity of some of his ideas, which were frequently cited by mid-century British physicians, there exist to my knowledge no English translations of his work. His treatise on mental disease was, however, translated into German in the 1850s.

15. Wilhelm Griesinger, Die Pathologie und Therapie der psychischen Krankheiten, 2 Aufl. (Stuttgart: Adolf Krabbe, 1861), 213-275.

16. Griesinger, "The Prognosis in Mental Disease," 317-327.

17. When Griesinger introduced his reform plan he did so from a position of moderate fame; his textbook and prestigious role at the Charite had made him well-known both in Germany and abroad. British readers were thus able to partake in Griesinger's vision for psychiatry when the speech that first made it public was translated into English and published in the Journal of Mental Science the following year. Griesinger, "Care and Treatment of the Insane."

18. German E. Berrios, The History of Mental Symptoms: Descriptive Psychopathology since the Nineteenth Century (Cambridge: Cambridge University Press, 1995), 310.

19. Griesinger, Die Pathologie und Therapie. For Zeller's influence on Griesinger see Verwey, Psychiatry, 140-150.

20. Griesinger, Die Pathologie und Therapie, 1.

21. This kind of physiological conception of mind potentially foreclosed the possibility of 'free will', since it made volition subject to the same abstract reflexive action as emotion. On free will in late-Victorian thought, see Roger Smith, Free Will and the Human Sciences in Britain, 18701910 (London: Pickering and Chatto, 2013). It should be noted that eighteenth-century writers on the philosophy of mind, particularly Locke and Hume, discussed the interplay between the passions, ideas, and volition in ways that could also be read as suggesting no significant hierarchical distinction between these faculties. Nevertheless, such claims occurred within a framework of an abstract philosophical conception of mind; to conceive of emotions, ideas, and the will as similar, and equal, physiological operations of the brain have arguably had far greater consequences for perceptions of mental pathology in the modern period.

22. Griesinger, Die Pathologie und Therapie, 25. 
23. Maudsley's nosology of 1867 was one of the first to put forward a type of madness in which the emotions were the only part of the mind affected, dividing thus the milder forms of insanity into 'affective' and 'ideational'.

24. Griesinger, Die Pathologie und Therapie, 26.

25. Griesinger, Die Pathologie und Therapie, 32.

26. Griesinger, Die Pathologie und Therapie, 33.

27. Griesinger, Die Pathologie und Therapie, 34.

28. Griesinger, Die Pathologie und Therapie, 213.

29. Griesinger, Die Pathologie und Therapie, 214.

30. Griesinger, Die Pathologie und Therapie, 215.

31. Griesinger, Die Pathologie und Therapie, 215-216.

32. Griesinger, Die Pathologie und Therapie, 227. For an account of the evolution of pain without organic injury, see Andrew Hodgkiss, From Lesion to Metaphor: Chronic Pain in British, French and German Medical Writings, 1800-1914 (Amsterdam: Rodopi, 2000). Chapter 4, "Reflexion and Depression" discusses psychological reflex action according to Müller, Griesinger, and Laycock in relation to developments of ideas about 'pain without lesion'. Hodgkiss's book provides important historical context to current medical views regarding bodily 'symptoms' without apparent organic cause, and concurrent debates about 'psycho-somatic illness'.

33. Griesinger, Die Pathologie und Therapie, 228.

34. Cf. Maudsley on simple melancholia, Chapter 5.

35. Griesinger, Die Pathologie und Therapie, 228-229. As will be seen in Chapter 5, Maudsley developed this model of simple melancholia in more detail in the last decade of the century, arguing that the ability of simple melancholics to reason about their suffering meant that they were more likely to commit suicide than melancholics whose illness was so severe that they had developed delusional thinking.

36. Biographical accounts of Maudsley can be found in: Aubrey Lewis, "Henry Maudsley: His Work and Influence (25th Maudsley Lecture)," Journal of Mental Science 407 (1951): 260-277; Trevor Turner, "Henry Maudsley: Psychiatrist, Philosopher, and Entrepreneur," in The Anatomy of Madness: Essays in the History of Psychiatry, Vol. III: The Asylum and Its Psychiatry, eds. William F. Bynum, Roy Porter, and Michael Shepherd (London: Routledge, 1988), 151-187; Michael Collie, Henry Maudsley: Victorian Psychiatrist: A Bibliographical Study (Winchester: St Paul's Bibliographies, 1988). Maudsley has received particular attention for his views on sex and degeneration, see e.g. Elaine Showalter, The Female Malady: Women, Madness, and English Culture, 1830-1980 (London: Virago, 1987); Daniel Pick, Faces of Degeneration: A European Disorder, c. 1848-1918 (Cambridge: Cambridge University Press, 1989).

37. Maudsley, Physiology and Pathology of the Mind, 45.

38. Danziger, "British Psycho-Physiology," 138. 
39. Maudsley, Physiology and Pathology of the Mind, 45.

40. Maudsley, Physiology and Pathology of the Mind, 41.

41. Maudsley, Physiology and Pathology of the Mind, 41-42.

42. Maudsley, Physiology and Pathology of the Mind, 88-89.

43. Maudsley, Physiology and Pathology of the Mind, 103.

44. Maudsley, Physiology and Pathology of the Mind, 47. Emphasis in original.

45. Maudsley, Physiology and Pathology of the Mind, 108.

46. Maudsley, Physiology and Pathology of the Mind, 149-150. For the will as physiological reflex, see also Henry Maudsley, Body and Mind (London: Macmillan, 1870), 27.

47. Maudsley, Physiology and Pathology of the Mind, 129. While in a very general sense, the terms 'passions' and 'emotions' could be seen to constitute a traditional and a modern category respectively, they were used differently by different writers at the time, sometimes the two were deployed synonymously, sometimes to denote different feeling states (see Dixon, From Passions to Emotions). Taking note of this conundrum, Maudsley clarified his own usage: 'It may be thought, perhaps, that it would not be amiss if something were now said of the difference between passion and emotion, inasmuch as the terms have hitherto been used almost indifferently. This, however, is scarcely necessary in dealing only with their general nature, which is fundamentally the same; every so-called emotion, when carried to a certain pitch, becomes a veritable passion' (p. 141).

48. Maudsley, Physiology and Pathology of the Mind, 134-135.

49. Maudsley, Physiology and Pathology of the Mind, 135.

50. Maudsley, Physiology and Pathology of the Mind, 137. Emphasis in original.

51. Maudsley, Physiology and Pathology of the Mind, 139.

52. Maudsley, Physiology and Pathology of the Mind, 140.

53. On emotion and its bodily manifestations, cf. Alexander Bain and William James, respectively, for two related but importantly different models. For Bain, the physical reactions accompanying different feelings were central to the problem of the tension between emotion and volition. While Bain argued, as did Maudsley, that emotions could be successfully regulated or supressed through habit, he was primarily concerned with those bodily manifestations of emotion which he considered to be 'voluntary', such as gestures and facial expressions (to be contrasted with involuntary' reactions like blushing) rather than with the feelings themselves. Alexander Bain, The Emotions and the Will (London: John W. Parker and Son, 1859), esp. 398-402. For James, the bodily manifestations were the starting point, i.e. these reactions came first, and would consequently produce the psychological feeling. William James, "What Is an Emotion," Mind 9 (1884): 189-190.

54. Maudsley, Physiology and Pathology of the Mind, 141. 
55. Maudsley, Physiology and Pathology of the Mind, 197. The practice of taking a person's medical 'history' was becoming standard practice in the mid-to-late nineteenth century. This development was gradually aided by the introduction of medical certificates, which explicitly asked medical officers to provide background information about new patients such as 'previous attacks', 'hereditary history', 'pre-disposing causes', and 'exciting (or immediate) causes'.

56. Maudsley, Physiology and Pathology of the Mind, 199.

57. Maudsley, Physiology and Pathology of the Mind, 322.

58 . Which appeared in numerous editions over several decades.

59. Jean-Étienne Dominique Esquirol, Mental Maladies: A Treatise on Insanity (Philadelphia: Lea \& Blanchard, 1845 [1838]), 209.

60. Bucknill and Tuke, A Manual of Psychological Medicine, 152, 181.

61. Bucknill and Tuke, A Manual of Psychological Medicine, 181-194.

62. Maudsley, Physiology and Pathology of the Mind, 322.

63. Maudsley, Physiology and Pathology of the Mind, 302.

64. (Author unknown) "Baillarger and Falret on a new species of insanity. Remarks on a variety of insanity, the paroxysms of which are characterized by two regular periods, the one of depression and the other of excitement by Dr. Baillarger," The American Journal of Insanity 11, No. 3 (185455): 230.

65. "Baillarger and Falret," 234. See also Jean-Pierre Falret, "De la folie circulaire ou forme de maladie mentale characterisée par L'alternative réguliere de la manie et de la mélancolie," Bulletin de L'Academie Nationale de Médicine, Paris (1851); German E. Berrios, "Melancholia and Depression during the Nineteenth Century: A Conceptual History," British Journal of Psychiatry 153 (1988): 301-302.

66. Maudsley, The Pathology of Mind, 382.

67. Thomas S. Clouston, "Report of the Physician-Superintendent for the Year 1881," Annual Report for the Royal Edinburgh Asylum for the Insane, Morningside, Royal Edinburgh Asylum (1882), 14. Maudsley later expressed a view closer to Clouston's, suggesting that in the 'folie circulaire of French authors the person is as unlike in thought, feeling and conduct as two persons of different character'. Henry Maudsley, "The Physical Conditions of Consciousness," Mind 2, No. 48 (1887): 506.

68. Savage, Insanity and Allied Neuroses, 122.

69. Savage, Insanity and Allied Neuroses, 123. For other contemporary views on circular insanity in British asylum patients, see e.g. Bucknill and Tuke, Manual of Psychological Medicine, 4th ed., 137-138, 304; Sankey, "On Melancholia," 191; D.G. Thomson, "The Prognosis in Insanity," Journal of Mental Science 29 (1883): 194-195; W. Herbert Packer, "A Case of Circular Insanity (Folie Circulaire)," Journal of Mental Science 30 (1884): 62-64. 
70. Savage's remark that circular insanity was unusual among British lunatics reveals little about different experiences of national asylum populations, and much about domestic coherence in knowledge and practices. Callard makes a similar remark in regards to Carl Westphal's model of agoraphobia, suggesting that presentations of 'remarkably similar symptomatologies need not be read as an empirical proof of how individuals in different countries were presenting with identical agoraphobic symptoms. Rather, those similarities could point to how potent Westphal's initial account was in providing compelling tropes and vignettes that were taken up elsewhere.' Felicity Callard, “'The Sensation of Infinite Vastness'; Or, the Emergence of Agoraphobia in the Late 19th Century," Environment and Planning D: Society and Space 24 (2006): 878.

71. See Engstrom, Clinical Psychiatry.

72. Griesinger, Die Pathologie und Therapie, 213.

73. Richard von Krafft-Ebing, Lebrbuch der Psychiatrie auf klinischer Grundlag: für practische Ärzte und Studirende (Stuttgart: Ferdinand Enke, 1880-1897).

74. Richard von Krafft-Ebing, A Text-Book of Insanity Based on Clinical Observations (New York: Classics of Psychiatry \& Behavioral Sciences Library, 1992).

75. Richard von Krafft-Ebing, Die Melancholie: Eine klinische Studie (Erlangen: Ferdinand Enke, 1874), 1-4, 6. Mental pain as a symptom of melancholia is further discussed in Chapter 5 .

76. Krafft-Ebing, Melancholie, 3-6, 9-11.

77. Krafft-Ebing, Textbook of Insanity, 49.

78. Krafft-Ebing, Melancholie, 5.

79. Krafft-Ebing, Melancholie, 65.

80. Roy Porter, "Nervousness, Eighteenth and Nineteenth Century Style: From Luxury to Labour," in Cultures of Neurasthenia from Beard to the First World War, ed. Marijke Gijswijt-Hofstra (Amsterdam and New York: Rodopi, 2001), 38.

81. Janet Oppenheim, 'Shattered Nerves': Doctors, Patients, and Depression in Victorian England (Oxford: Oxford University Press, 1991).

82. George Beard, A Practical Treatise on Nervous Exhaustion (Neurasthenia), Its Symptoms, Nature, Sequences, Treatment (New York: William Wood, 1880), 15-69.

83. Judith Misbach and Henderikus J. Stam, "Medicalizing Melancholia: Exploring Profiles of Psychiatric Professionalization," Journal of the History of the Behavioral Sciences 42, No. 1 (2006): 41-59.

84. George Cheyne, The English Malady, Or, A Treatise of Nervous Diseases of All Kinds, as Spleen, Vapour, Lowness of Spirits, Hypochondriacal or Hysterical Distempers (London: George Strahan, 1733). 
85. William F. Bynum, "The Nervous Patient in Eighteenth- and NineteenthCentury Britain: The Psychiatric Origins of British Neurology," in The Anatomy of Madness: Essays in the History of Psychiatry, Vol. I: People and Ideas, eds. W.F. Bynum, Roy Porter, and Michael Shepherd (London: Routledge, 1985), 91. See also Porter, "Nervousness," 32-36.

86. Bynum, "The Nervous Patient," 91. This idea must moreover be placed in its wider medical context. Anne Vila has shown how weakness, strength, and vitality, inscribed onto nerves and tissue and linked to the body's 'vital fluids' (and both explicitly and implicitly gendered and moralised), accounted for unhealth more generally in the Enlightenment. Anne C. Vila, Enlightenment and Pathology: Sensibility in the Literature and Medicine of Eighteenth-Century France (Baltimore and London: The Johns Hopkins University Press, 1998), 65-73, 94-107, 229-240.

87. British medical accounts of nervous disorders abound in this period. See, for instance: (author unknown) "Nervous Influence," Journal of Psychological Medicine and Mental Pathology 5 (1852): 221-229; Cyril Bennet, The Modern Malady, or, Sufferers from "Nerves" (London: Edward Arnold, 1890); Edward Jarvis, "The Overworked Mind," Journal of Psychological Medicine and Mental Pathology 5 (1852): 257-276; George Lefevre, "An Apology for the Nerves, Or Their Influence and Importance in Health and Disease," Journal of Psychological Medicine and Mental Pathology 2 (1849): 90-114; James Ross, Handbook of the Diseases of the Nervous System (London: J \& A Churchill, 1885); Thomas Stretch Dowse, On Brain and Nerve Exhaustion: 'Neurasthenia' (London: Baillière, Tindall \& Cox, 1880).

88. Porter, "Nervousness," 37.

89. Anson Rabinbach, The Human Motor: Energy, Fatigue, and the Origins of Modernity (Berkeley: University of California Press, 1992), 23-25, 121, 124-127.

90. Berrios, "Melancholia and Depression," 300-301.

91. Michael Neve, "Public Views of Neurasthenia: Britain 1880-1930," in Cultures of Neurasthenia, ed. Gijswijt-Hofstra, 154-157; Porter, "Nervousness, Eighteenth and Nineteenth Century Style," 42-43; Chandak Sengoopta, “'A Mob of Incoherent Symptoms?' Neurasthenia in British Medical Discourse, 1860-1920," in ed. Gijswijt-Hofstra, Cultures of Neurasthenia, 107-110; Thomson, "Neurasthenia in Britain," 84-90.

92. Daniel H. Kitchen, "Lectures on Insanity. Lecture II: Melancholia, Delivered at Charity Hospital, October and November 1876," Ohio Medical and Surgical Journal 2, No. 3 (1877): 237-256.

93. Ira Russell, "Melancholia," The Alienist and Neurologist 2 (1881): 201.

94. Russell, "Melancholia," 202.

95. Russell, "Melancholia," 205. 


\section{A. JANSSON}

Open Access This chapter is licensed under the terms of the Creative Commons Attribution 4.0 International License (http://creativecommons.org/licenses/ by $/ 4.0 /$ ), which permits use, sharing, adaptation, distribution and reproduction in any medium or format, as long as you give appropriate credit to the original author(s) and the source, provide a link to the Creative Commons license and indicate if changes were made.

The images or other third party material in this chapter are included in the chapter's Creative Commons license, unless indicated otherwise in a credit line to the material. If material is not included in the chapter's Creative Commons license and your intended use is not permitted by statutory regulation or exceeds the permitted use, you will need to obtain permission directly from the copyright holder.

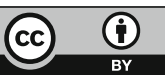

